\title{
Inauguração da Sala de Conferências "Professor Anhaia Mello" na FAUUSP
}

Prof. José Luiz Caruso Ronca:

Convido a Prof ${ }^{a}$ Gilda Collet Bruna, Diretora desta escola, a participar da mesa da inauguraçāo desta sala. Com a inauguraçāo, vamos também ter a honra de ouvir o Prof. Charles Beylier, da Universidade Federal do Ceará, especialista em Roger Bastide, que se prontificou a vir à nossa faculdade oferecer uma conferência sobre o pensamento de Roger Bastide e sobre o desenvolvimento sustentado à luz da Antropologia e da Sociologia. Neste momento, convido o Prof. Charles Beylier a participar da mesa.

A reforma desta sala foi conseguida por meio de verbas da CAPES - Coordenadoria de Aperfeiçoamento do Pessoal de Ensino Superior do Ministério da Educaçāo. Vai aqui meu agradecimento e minha homenagem à CAPES pelos esforços que tem demonstrado com o nosso curso, para mantê-lo ao nível de um dos melhores do país, o único a nível de doutorado.

Com esta inauguração queremos relembrar a figura do Prof. Anhaia Mello e, nesse sentido, eu gostaria de convidar, à mesa, duas pessoas que tiveram maior relacionamento com este professor: o Prof. Lauro Bastos Birkholz, que durante anos foi seu assistente e que neste momento nos honra com a sua presença: e o Prof. Brenno Cyrino Nogueira, que foi também seu assistente.

Não poderia deixar de convidar, tambem um colega. Prof. Carlos Eduardo Zahn, que junto comigo vem lecionando desde 1973 nesta Faculdade, sendo que nesta disciplina de pós-graduaçāo, ligada a cidade e à organização do espaço, tomamos a iniciativa de convidar o Prof. Charles Beylier.

Nesse momento, em uma homenagem a quem tanto devemos, o Prof. Anhaia Mello, eu gostaria que o Prof. Brenno usasse da palavra e nos dissesse alguma coisa sobre sua obra, como ela frutificou e como foram seus esforços para conseguir este prédio para nossa Faculdade.

Prof. Brenno Cyrino Nogueira:

Inicialmente eu gostaria de cumprimentar todos os componentes da mesa, especialmente o Prof. Charles Beylier e agradecer a presença de todos neste ato em que homenageamos o insígne professor fundador desta Faculdade.

Falar do Prof. Luiz Ignácio Romeiro de Anhaia Mello é falar de uma notável e extraordinária figura humana que influenciou de modo marcante a vida intelectual de nosso Estado, e até mesmo de nosso pais em boa parte deste século. É quase querer falar de um mito, por aquilo que ele representou nas idéias e no ensino de Arquitetura e Urbanismo.

Nasceu ele no final do século passado a vinte e três de agosto de mil e oitocentos e noventa e um (23/08/1891) na cidade de ltu e faleceu, com oitenta e três anos, no dia dezesseis de janeiro de mil novecentos e setenta e quatro (16/01/1974), nesta cidade de São Paulo.

Era filho do engenheiro Luis de Anhaia Mello, um dos cinco primeiros professores e fundadores da Escola Politécnica em 1893, marco do então espírito de modernização e inserção de nossa sociedade no propósito de industrialização que germinou e frutificou em São Paulo. mudando verdadeiramente. daí por diante, a face do país.

Seu pai foi ainda professor e vice-diretor da Escola Politécnica (1895-1899), sendo lembrado pela história como um dos pioneiros da industrializaçāo em Sāo Paulo, como foi também o Conde Antônio Álvares Penteado, que fez 
Foto 1

Sala Professor Dr. Luiz de Anhaia Mello

Foto de Jorge Maruta

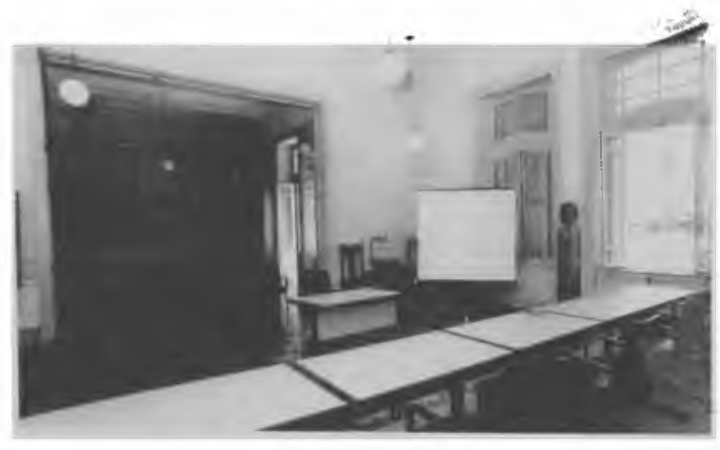

Foto 2

Sala Professor Dr. Luiz de Anhaia Mello

Foto de Jorge Maruta

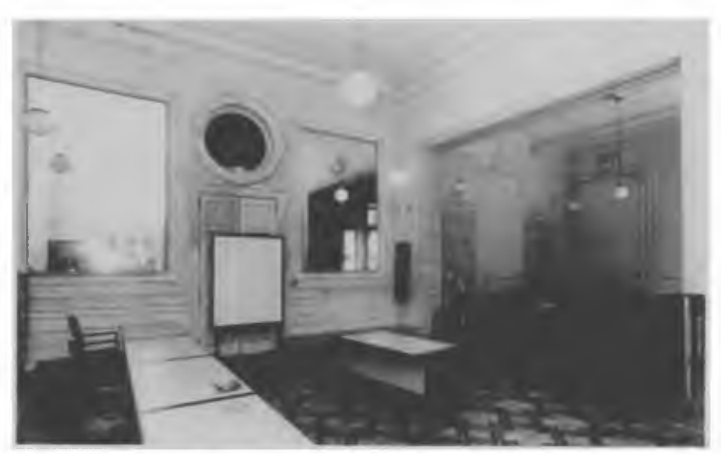

construir o prédio onde ora nos achamos, mais tarde doado por seus filhos para a fundaçāo desta Faculdade.

Professor, arquiteto e urbanista, Luiz Ignácio Romeiro de Anhaia Mello iniciou sua formação intelectual no Colégio São Luis, de ltu. onde fez o curso secundário, de 1904 a 1908. Realizou, em seguida, o curso superior na Escola Politécnica de São Paulo, de 1909 a 1913, onde diplomou-se Engenheiro-Arquiteto, o único desta modalidade formado naquele ano. Foi aluno do arquiteto Francisco de Paula Ramos de Azevedo, nascido em 1851 e morto em 1928, o mais influente da época em São Paulo, de quem recebeu forte influência e com quem, mais tarde, trabalhou.

Em 1918. Anhaia Mello iniciou sua brilhante carreira de professor, à qual, sem dúvida dedicou parte significativa de sua vida, ingressando no corpo docente da Escola Politécnica.

Passou, em seguida, a Mestre Interino, em 1919, e a Professor catedrático. em 1926, tendo lecionado as matérias de Composição Arquitetônica, Estética e Urbanismo para os alunos dos cursos de Engenheiro-Arquiteto e Engenheiro Civil, este muito mais concorrido do que aquele.

Lecionou também, após fundada a Faculdade de Arquitetura e Urbanismo da USP, as matérias de Teoria da Arquitetura e Urbanismo. Incomparável conhecedor de Estética, fortemente embasada na Filosofia, nāo somente compreendeu os clássicos da História da Arquitetura, como foi também profundo conhecedor das obras dos arquitetos então modernos: Le Corbusier. Frank Lloyd Wright, Gropius e tantos outros mestres renovadores da Arquitetura em nosso século.

Distinguiu-se mormente, porém, como teórico e ideólogo do Urbanismo, modernizando e ampliando nossa cultura nesse campo. Sua vocação foi, sem dúvida, desde os inícios da atividade docente, a decifração do enigma urbanístico, antevendo os problemas com que, nesse aspecto, a humanidade se defrontaria.

Opôs-se, desde os anos 30, quando iniciou o ensino de Urbanismo na Escola Politécnica, sob uma ótica moderna, às tendências das Belas Artes, do Sanitarismo e da chamada "Engenharia Municipal de Serviços Públicos"

Era notável o conhecimento que possuia sobre as obras e as teorias dos mestres do Urbanismo e do Planejamento mundiais. Dono de uma vasta cultura técnica e humanista, fruindo o dom da palavra, influenciou, com suas brilhantes aulas, geraçōes de profissionais. ao mesmo tempo em que transferia para o meio social seus conhecimentos, principalmente por meio de sua incansávei e fascinante atividade de conferencista.

Deixou também várias obras que marcaram a atividade prática no campo dos serviços públicos e no próprio planejamento de São Paulo. Aliou a tudo isso uma enorme experiência de vivência administrativa, sendo extensa a lista dos cargos de importância que ocupou. Primeiramente Vereador à Câmara Municipal de Sāo Paulo (1920), Presidente do Instituto de Engenharia (1930). Diretor da Escola Politécnica (1930), Prefeito de São Paulo (1930-1931), Secretário de Viação e Obras Públicas do Estado (1941), Diretor da Faculdade de Filosofia da USP (1941): Membro da Comissão de localização da Nova Capital da República (1947), Vice-Reitor da USP (1950). Membro da Comissão Orientadora do Plano do Município de Sāo Paulo (1953-1961). Presidente da Comissão da Cidade Universitária da USP (1948), Vice-Reitor da USP (1950), Diretor do FUNDUSP (1957) e tantos outros encargos. 
Mas sua maior obra foi, sem dúvida, a criação da FAUUSP da qual foi por diversas vezes Diretor: em 1948, quando da sua fundação e mais tarde de 1959 a 1961. Era a realização do que pregou durante toda a sua vida, que foi a ampliação do conhecimento de Arquitetura e Urbanismo e o aprofundamento do seu papel em nosso meio social, vislumbrando a contribuição que poderia dar para os destinos do país.

Aqui moldou ele os primeiros profissionais de Arquitetura formados fora das Escolas de Engenharia. Aqui, fundou ele o Centro de Pesquisas e Estudos Urbanísticos - CPEU - que, sob a sua direção, de 1957 a 1960, tanto se esforçou para elevar o nivel dos conhecimentos e da prática do Planejamento Urbano e Regional.

Aqui semeou a fé, a confiança no conhecimento e na cultura, como instrumentos de transformaçāo do pais. É a sua maior lição, que está também entranhada na própria idéia da Faculdade.

É por isso que estamos aqui reverenciando a sua memória, reavivando-a na esperança de que os valores de nossa cultura não sejam tragados pela voragem dos erros, das incompreensōes e dos dogmatismos deste conturbado século.

Desejo, finalmente, prestar ainda nossa homenagem ao Prof. Lauro Bastos Birkholz que, tendo sido aluno, assistente e, posteriormente, professor da cadeira de Urbanismo regida pelo Prof. Anhaia Mello, vem como seu verdadeiro herdeiro, dando tudo de si para levar adiante essa difícil missāo.

Quero também apresentar à Profa Gilda Collet Bruna, Diretora desta Faculdade, ao Prof. José Luiz Caruso Ronca. Presidente da Comissão de Pós-Graduação, à Comissão de Pós-Graduação e à Congregaçāo desta Faculdade, os cumprimentos pela iniciativa de inauguraçāo da Sala Professor Dr. Luiz de Anhaia Mello.

\section{Prof. José Luiz Caruso Ronca:}

Dou a palavra agora ao Prof. Lauro Bastos Birkholz para contar alguma coisa de sua experiência de vida com o Prof. Anhaia Mello.

\section{Prof. Lauro Bastos Birkholz:}

Minhas senhoras e meus senhores, para mim é um momento muito agradável estar sentado nesta mesa, em que estāo também todos aqueles que trabalharam comigo a vida inteira. Aqueles que, hoje, carregam um estandarte que eu passei à sua māo, sendo que um é Presidente da Comissão de Pós-Graduação, outra é Diretora da Faculdade, mais dois são professores doutores que trabalham intensamente nesta Faculdade. Ninguém poderia estar tão satisfeito quanto eu vendo, ainda vivo, o resultado da minha obra.

Na mesma ordem de idéias, fico imensamente satisfeito de poder falar alguma coisa do Prof. Anhaia Mello. Ele foi o Diretor desta Escola e muito pouca gente sabe os problemas que teve que enfrentar.

Eu gostaria de citar fatos. Para poder formar uma faculdade, era preciso um local, o que geralmente não é muito fácil de se encontrar. Ele sabia que esta casa - do Conde Penteado - nāo estava sendo usada e conseguiu, com um esforço sobre-humano, convencer os herdeiros a doar este prédio à Universidade de São Paulo para que se pudesse fundar a Faculdade de Arquitetura e Urbanismo. Mas haviam mais problemas graves que precisavam ser resolvidos.
Foto 3

Sala Professor Dr. Luiz de Anhaia Mello

Folo de Jorge Maruta

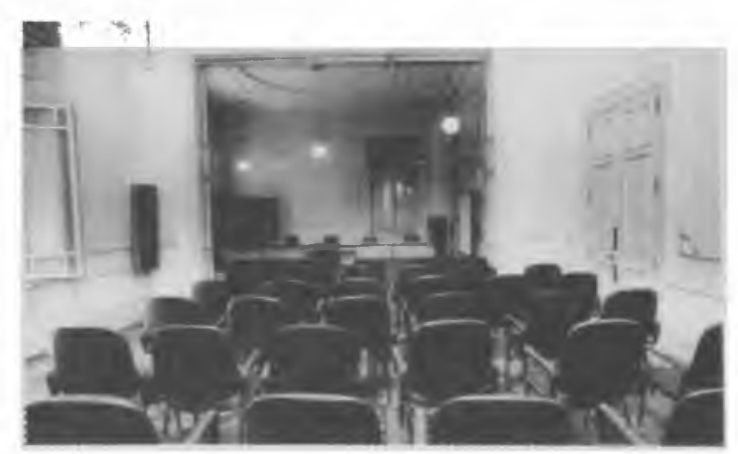

Pós - A. Prog. Pós-Grad. Arquit. Urb. FAUUSP. Sáo Paulo n. 4 p. 15-38 dez. 1993 
Fotos 4 e 5

Busto do Prof. Anhaia Mello

Foto de Jorge Maruta
Não era possivel continuar existindo o curso de Engenheiro-Arquiteto na Escola Politécnica da USP e, ao mesmo tempo, manter outro curso de Arquitetura na Universidade de Sāo Paulo. Assim, precisou convencer a Congregação, da qual ele fazia parte, que era de toda a conveniência que a Escola Politécnica abrisse mão do curso de Arquitetura para que esse curso pudesse funcionar no novo prédio. Ninguém imaginava a dificuldade. Por exemplo, é a mesma coisa que tentar convencer a Faculdade de Medicina que o curso de Obstetrícia tivesse que ser separado da Faculdade, para constituir uma escola de Obstetrícia independente, na mesma Universidade. Ele conseguiu isso com unanimidade da Congregação, que abriu mão do curso de Engenheiros-Arquitetos para que se formassem arquitetos nessa Faculdade.

Havia um segundo problema muito grave e difícil, que era o de ser reconhecido o curso, com muita burocracia, dependendo de aprovação do Conselho Nacional de Educação. O Prof. Anhaia Mello levou o problema a esse Conselho e o relator, no seu despacho, dizia que em se tratando de um curso a ser destacado do curso da Escola Politécnica de São Paulo, uma das melhores escolas de engenharia do Brasil, nada precisaria ser feito para verificar o seu valor, podendo ser aprovado sem discussão. Foi aprovado por unanimidade.

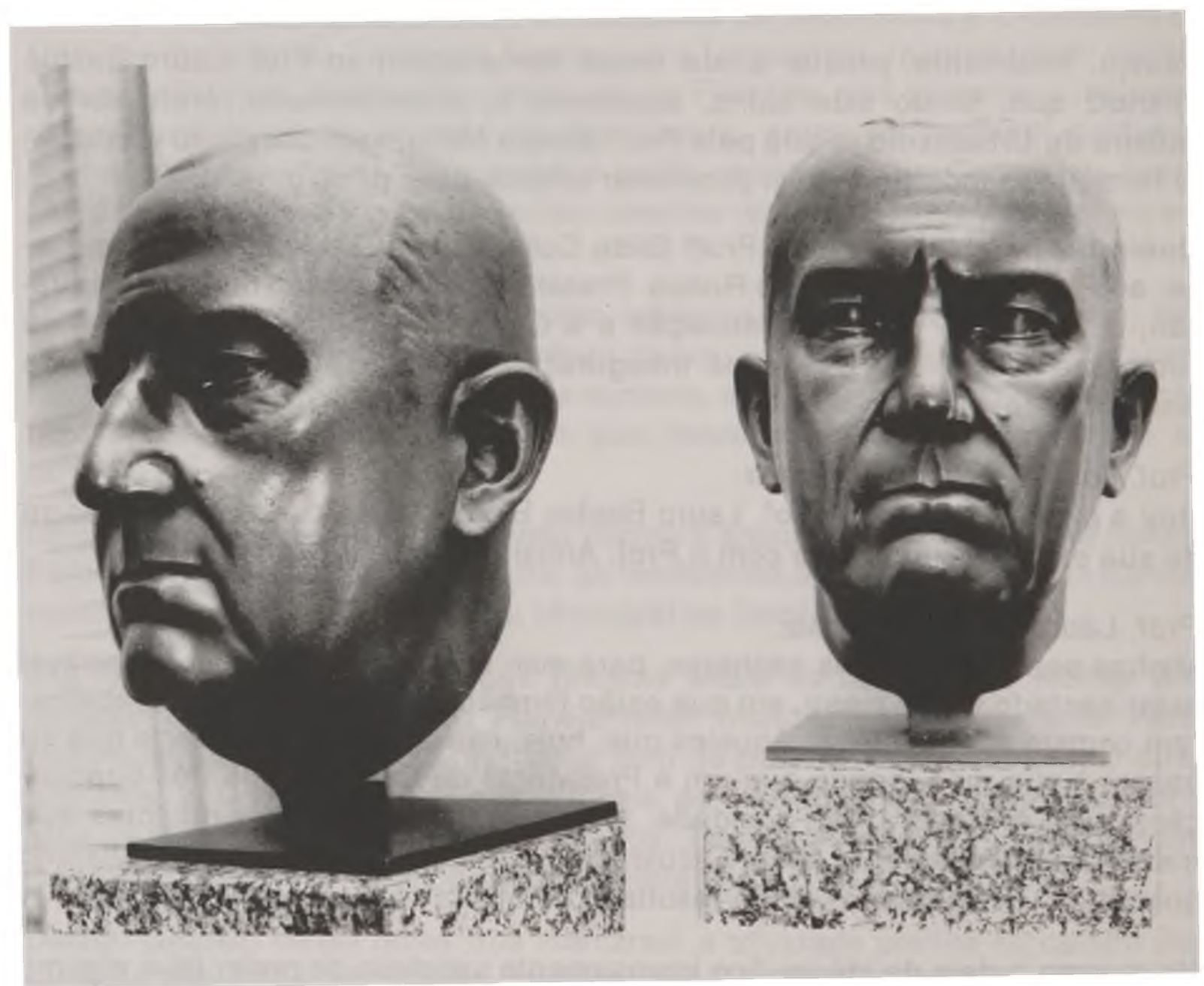

Esses três fatos mostram a dificuldade que o Prof. Anhaia Mello teve que enfrentar. Na qualidade de seu assistente e de Diretor do Centro de Estudos e Pesquisas Urbanisticas, depois que ele se aposentou, eu continuei nesta Faculdade até que me aposentei. E, estando aposentado, tenho a satisfação de ver colaboradores, hoje, aqui nesta mesa. Muito obrigado.

Prof. José Luiz Caruso Ronca:

Passo a palavra à Profa Gilda Collet Bruna para que, na qualidade de Diretora. declare inaugurada a sala. 
Em primeiro lugar, preciso dizer da minha satisfação de poder estar aqui comemorando, com a minha família da FAU, essa possibilidade que hoje se realiza. Acho muito importante comemorar a nossa história que, certamente, é a história da gente que está aqui, que cresceu neste ambiente da FAU, sob a orientaçāo do Prof. Lauro. Mas também de vocês, porque a FAU é maior: é a graduação e, hoje, é a pós-graduaçāo.

Em 1948, ela começou como uma Faculdade no nivel de graduaçäo: em 1973 abriu seu curso de pós-graduação. Inclui, acredito, pratıcamente todos os que estão aqui e que têm um pouco do seu coração ligado à FAU. Isso nem sempre se pode comemorar, e essa é a minha satisfação. de um lado. Por outro lado, queria parabenizar o Prof. Ronca e a Pós-Graduação por essa iniciativa e pela possibilidade de conseguir que se desse mais um passo na ocupaçāo deste prédio, possibilitando ter uma sala própria para se receber uma visita, para apresentar uma tese com a dignidade que se está tendo no momento.

Queria também dar as boas-vindas ao Prof. Beylier, cuja conferência também lembra um pouco da nossa história. Quando foi inaugurada a Universidade de São Paulo não tínhamos professores e ele evocará a história da atuação dos professores franceses que estiveram aqui no início da historia da USP especialmente de Roger Bastide.

Com isto, quero declarar inaugurada esta sala, em honra do Prof. Luiz Ignácio de Anhaia Mello, e me congratular com os professores que estão aqui e com todos vocês. Muito obrigada.

\section{Conferência do Prof. Charles Beylier sobre o "Pensamento do Sociólogo e Antropólogo Roger Bastide"}

Quero agradecer o convite que me foi feito para participar desta inauguraçāo, pois tanto a homenagem ao fundador desta Faculdade quanto a renovaçāo deste prédio demonstram a preocupação que a diretoria da FAU tem em manter viva a memória.

A memória fica viva quando tem instituiçōes. quando tem prédios, quando tem arte, que mantem a história dentro das próprias linhas, lanto da Arquitetura. como também da pintura. Sabemos que não há história sem memória e um povo que perde a memória perde, portanto, a sua própria história, quer dizer, a sua identidade.

Assim, acho uma grande coisa quando passo na avenida Paulista e vejo prédios magníficos pela altura que eles têm e. ao mesmo tempo. graças a Deus, de vez em quando, no meio deles, uma pequena casa que ainda resistiu e que vem lembrar alguma coisa da História. Isso é o problema que enfrentam todos os países do mundo: manter a História do passado e construir o futuro.

Por isso, agradeço muito este convite e, sobretudo, a oportunidade de falar de Roger Bastide.

Nāo conheci Roger Bastide. Quando comecei a me preocupar com o problema da interpenetração de culturas em 1975, ele já tinha morrido e repousava no Cemitério de Anduze.

Tornel-me preocupado com este problema porque, vivendo desde 1965 em Campina Grande, na Paraíba, fiquei impressionado ao ver como as pessoas com descendência indigena ou africana e que estavam engajadas, naquela 